\title{
PC index as a proxy of the solar wind energy that entered into the magnetosphere: 2. Relation to the interplanetary electric field $E_{\mathrm{KL}}$ before substorm onset
}

\author{
OA Troshichev ${ }^{*}$ (I) and DA Sormakov
}

\begin{abstract}
This paper (the second of a series) presents the results of statistical investigation of relationship between the interplanetary electric field $E_{\mathrm{KL}}$ and the Polar Cap (PC) index in case of magnetic substorms (1998-2001), which have been analyzed in Troshichev et al. (J. Geophys. Res. Space Physics, 119, 2014). The PC index is directly related to the $E_{\mathrm{KL}}$ field variations on interval preceding the substorm sudden onset (SO): correlation $R>0.5$ is typical of more than $90 \%$ of isolated substorms, $80 \%$ of expanded substorms, and $99 \%$ of events with coordinated $E_{K L}$ and PC jumps. The low or negative correlation observing in $\sim 10 \%$ of examined substorms suggests that the solar wind flow measured by the Advanced Composition Explorer (ACE) spacecraft in the Lagrange point L1 did not encounter the magnetosphere in these cases. Examination of the delay times $\Delta T$ in the response of $P C$ index to $E_{K L}$ variations provides the following results: (1) delay times do not depend on separate solar wind parameters, such as solar wind speed $V_{x}$ and interplanetary magnetic field (IMF) $B_{Z}$ component, contrary to general conviction, (2) the $\Delta T$ value is best controlled by the $E_{\mathrm{KL}}$ field growth rate $\left(\mathrm{d} E_{\mathrm{KL}} / \mathrm{dt}\right)$, (3) the lower $\Delta T$ limit $(5-7 \mathrm{~min}$ is attained under conditions of the higher $E_{K L}$ growth rate, and (4) the PC index provides the possibility to verify the solar wind flow transportation time from ACE position (where the solar wind speed is estimated) to magnetosphere. These results, in combination with data testifying that the substorm onsets are related to the PC precursors, demonstrate that the PC index is an adequate ground-based indicator of the solar wind energy incoming into the magnetosphere.
\end{abstract}

Keywords: Interplanetary electric field $E_{\mathrm{KL}}$; PC index; Magnetic substorms; Delay time; Solar wind parameters growth rate; Solar wind energy input

\section{Background}

In the first paper of a series (Troshichev et al. 2014), the statistical relationships between the Polar Cap (PC) and $\mathrm{AL}$ indices for the isolated and expanded magnetic substorms have been studied. It was demonstrated that magnetic substorms are preceded by the PC index growth and start usually when the PC index exceeds some threshold $\sim 1.5 \pm 0.5 \mathrm{mV} / \mathrm{m}$. The substorm sudden onsets (SO) are related to sharp increases in the $\mathrm{PC}$ growth rate, and the linear dependency of the AL value on the PC index is typical of the periods before and after the sudden onsets, irrespective of the substorm type and intensity. Basing on these results, the conclusion was made that the PC index

* Correspondence: olegtro@aari.ru

Arctic and Antarctic Research Institute, St. Petersburg 199397, Russia can be regarded as a ground-based proxy of the solar wind energy that enters into the Earth's magnetosphere. To verify this idea, we need to have at our disposal either the direct data on variations of this energy (it is unlikely) or rely on the circumstantial evidences, such as the coupling functions, which are determined as the solar wind parameters combine providing the best correlation between the solar wind variations and the magnetosphere state.

The PC index has been introduced (Troshichev and Andrezen 1985; Troshichev et al. 1988) as a magnitude of the polar cap magnetic disturbance $\delta F$ normalized by the geoeffective interplanetary electric field value expressed by the formula of Kan and Lee (1979).

$$
E_{\mathrm{KL}}=V_{\mathrm{SW}}\left(B_{\mathrm{Y}}{ }^{2}+B_{\mathrm{Z}}^{2}\right)^{1 / 2} \sin ^{2} \theta / 2
$$


where $V_{\mathrm{SW}}$ is the velocity of the solar wind, $B_{\mathrm{Y}}$ and $B_{\mathrm{Z}}$ are the components of the interplanetary magnetic field (IMF), and $\theta$ is the angle between the IMF transverse component and the geomagnetic dipole. It should be noted that it is just interplanetary electric field $E_{\mathrm{KL}}$ that most closely corresponds to formulas for the optimal coupling function, which were derived by Newell et al. (2007, 2008) and Wang et al. (2014). Thus, the $E_{\mathrm{KL}}$ field can be regarded as a parameter related to the solar wind energy input into the magnetosphere.

Correlation between the 15-min averages of the $E_{\mathrm{KL}}$ field (shifted to the bow shock) and the 1-min values of polar cap magnetic activity $\delta F$ was examined in Troshichev et al. (1988). It was shown that correlation is optimal when a delay time $\Delta T \sim 20-25 \mathrm{~min}$ between the $E_{\mathrm{KL}}$ and the respective $\delta F$ variations is taken into account. Subsequent analysis (Stauning and Troshichev 2008) based on the 1-min $E_{\mathrm{KL}}$ and $\delta F$ values showed that the PC index begins to grow in about $10 \mathrm{~min}$ after the $E_{\mathrm{KL}}$ rises near the magnetosphere's nose; the index reaches its maximum at about $15-30 \mathrm{~min}$ after the $E_{\mathrm{KL}}$ maximizes. In the abovementioned studies, the relationship between $E_{\mathrm{KL}}$ and PC was examined regardless of the magnetosphere state or substorms. In the present study, the attention will be given to delay time $\Delta T$ providing the best correlation between $E_{\mathrm{KL}}$ and PC on intervals preceding the substorm onset and to dependency of $\Delta T$ values on the solar wind parameters.

\section{Methods}

The events with isolated and expanded substorms analyzed by Troshichev et al. (2014) (referred further as Paper 1) were served as a basis for the study of the relationships between the PC index and the interplanetary electric field $E_{\mathrm{KL}}$. Substorms in paper 1 have been selected basing on the magnetic disturbance sudden onsets (SO) in the aurora zone, determined as a decrease in the AL index of at least $100 \mathrm{nT}$ within $15 \mathrm{~min}$. Then, substorms were divided into isolated and expanded types: isolated substorms were the ones which arose out of a background of quiet conditions $(\mathrm{AL} \leq 200 \mathrm{nT})$ during the $3 \mathrm{~h}$ prior to $\mathrm{SO}$; expanded substorms were the ones which occurred against the background of the enhanced magnetic activity in the polar cap and aurora zone. Since the substorm sudden onset magnitude is linearly related to the value of PC at the SO moment $T_{0}$ (see paper 1 ), the substorms were further separated into groups by their initial intensity, i.e., according to the $\mathrm{PC}$ index value at the $\mathrm{SO}$ moment $\left(\mathrm{PC}_{0}\right)$, as follows: $\mathrm{PC}_{0}=0.5 \pm$ $0.25 \mathrm{mV} / \mathrm{m}, \mathrm{PC}_{0}=1 \pm 0.25 \mathrm{mV} / \mathrm{m}, \mathrm{PC}_{0}=1.5 \pm 0.25 \mathrm{mV} /$ $\mathrm{m}, \mathrm{PC}_{0}=2 \pm 0.25 \mathrm{mV} / \mathrm{m}$, etc.

Two approaches have been used in our epoch superposition analysis. In the first approach, the correlation between the $E_{\mathrm{KL}}$ and PC quantities was calculated on the 1-h interval preceding the sudden onset of each isolated or expanded substorm, the $\mathrm{SO}$ moment being used as a key date $T_{0}$ (Fig. 1a, b). In the second approach, we examine the time evolution of the $E_{\mathrm{KL}}$ and PC quantities on the 2-h interval preceding $\mathrm{SO}$, irrespective of the substorm type, and separated those events where the $E_{\mathrm{KL}}$ field sudden rise was obviously followed by the PC index jump. In these events, named as coordinated ones, the moment of the $E_{\mathrm{KL}}$ field rise beginning was taken as a key date $\left(T_{0}\right)$, and correlation between the $E_{\mathrm{KL}}$ and PC quantities was calculated over the time period $T_{0} \pm$ 30 min (Fig. 1c).

The $E_{\mathrm{KL}}$ field was calculated using the data on solar wind and IMF parameters reduced to the magnetopause, as they were presented at the GSFC/SPDF OMNI/Web interface http://omniweb.gsfc.nasa.gov. The PC index was taken as an average value of PCN and PCS indices derived by data from stations Thule (Greenland) and Vostok (Antarctica) to level off a possible asymmetry in magnetic activity produced by the IMF azimuthal component or/and the solar proton invasion in the opposite polar caps (see Troshichev and Janzhura (2012b)). The data with gaps were extrapolated if the gaps were less than $40 \%$ of the event data series; otherwise, events with data gaps were excluded from the analysis. As a result, the total number of examined events for the period 1998-2001 turned out to be $N=163$ for the isolated substorms, $N=983$ for the expanded substorms, and $N=261$ for the coordinated events.

Correlation between the $E_{\mathrm{KL}}$ field and PC index was calculated with allowance for delay time. The acting delay time of the $\mathrm{PC}$ response to the $E_{\mathrm{KL}}$ variation was determined for each event in the following manner: correlation between $E_{\mathrm{KL}}$ and $\mathrm{PC}$ was calculated under different time displacement $(\mathrm{dt})$ of $\mathrm{PC}$ relative to $E_{\mathrm{KL}}$, and the value of displacement providing the best correlation was identified as a delay time $(\Delta T)$. Taking into account that typical delay time in the response of PC index to the $E_{\mathrm{KL}}$ field variations is $\sim 15-25 \mathrm{~min}$ (Stauning and Troshichev 2008; Troshichev et al. 1988), the time shift $\mathrm{dt}$ was taken in range from 0 to $45 \mathrm{~min}$. The superposed epoch method was applied to each group with different $\mathrm{PC}_{0}$ to derive the time evolution of the mean $\mathrm{PC}$ and $\mathrm{AL}$ quantities in the course of a substorm event, the moment $T_{0}$ being taken as a key time.

\section{Results}

\section{Correlation between $E_{\mathrm{KL}}$ and $\mathrm{PC}$ on intervals preceding} the substorm sudden onset

Figure 2 shows the occurrence of events with different coefficients of correlation between $E_{\mathrm{KL}}$ and PC for events with isolated (a) and expanded (b) substorms and for coordinated events (c). One can see that correlation $R>0.5$ is valid for $92 \%$ of isolated substorms, for $81 \%$ of 

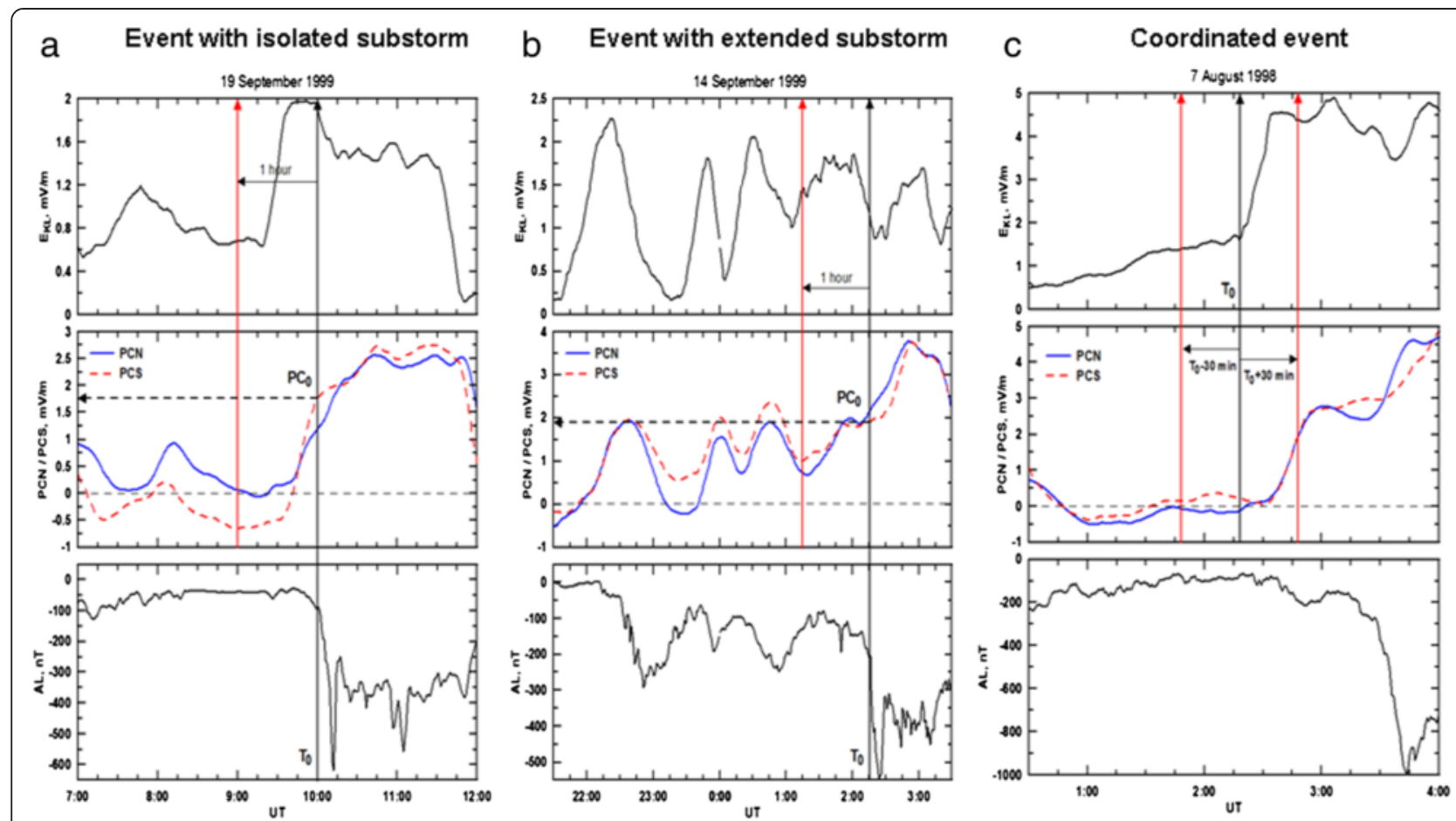

Fig. 1 Examples of time evolution of the $E_{K L}$ field and the $P C$ index on interval preceding the substorm sudden onset in the course of isolated (a) and expanded (b) substorms and coordinated events (c)

expanded substorms, and for more than $99 \%$ of coordinated events (the high correlation in the latter case is predetermined by the method used for the separation of the coordinated events). These results distinctly demonstrate that the PC index growth, preceding the substorm onset, is closely related to the appropriate rise in the $E_{\mathrm{KL}}$ field, although the close linkage between $E_{\mathrm{KL}}$ and $\mathrm{PC}$ in case of expanded substorms is essentially deformed by the high magnetic activity, serving as a background of the expanded substorm onsets.

Thus, the linear relationship between $\mathrm{PC}$ and $E_{\mathrm{KL}}$, suggested by Troshichev et al. (1988) relying on general statistical analysis of a large body of data, remains valid in particular case of the substorm development. It is noteworthy that $\sim 8 \%$ of events with isolated substorms and $\sim 20 \%$ of events with expanded substorms demonstrated the low $(R<0.5)$ or even negative $(R<0)$ correlation between $E_{\mathrm{KL}}$ and PC. Taking into account that all events under examination were chosen as related to the really observed substorm onsets, preceded by the distinct precursors in the PC index, conclusion is made that the solar wind observed on board the ACE spacecraft (at a distance of $\sim 1.5$ million kilometers upstream of the Earth) did not encounter the Earth's magnetosphere

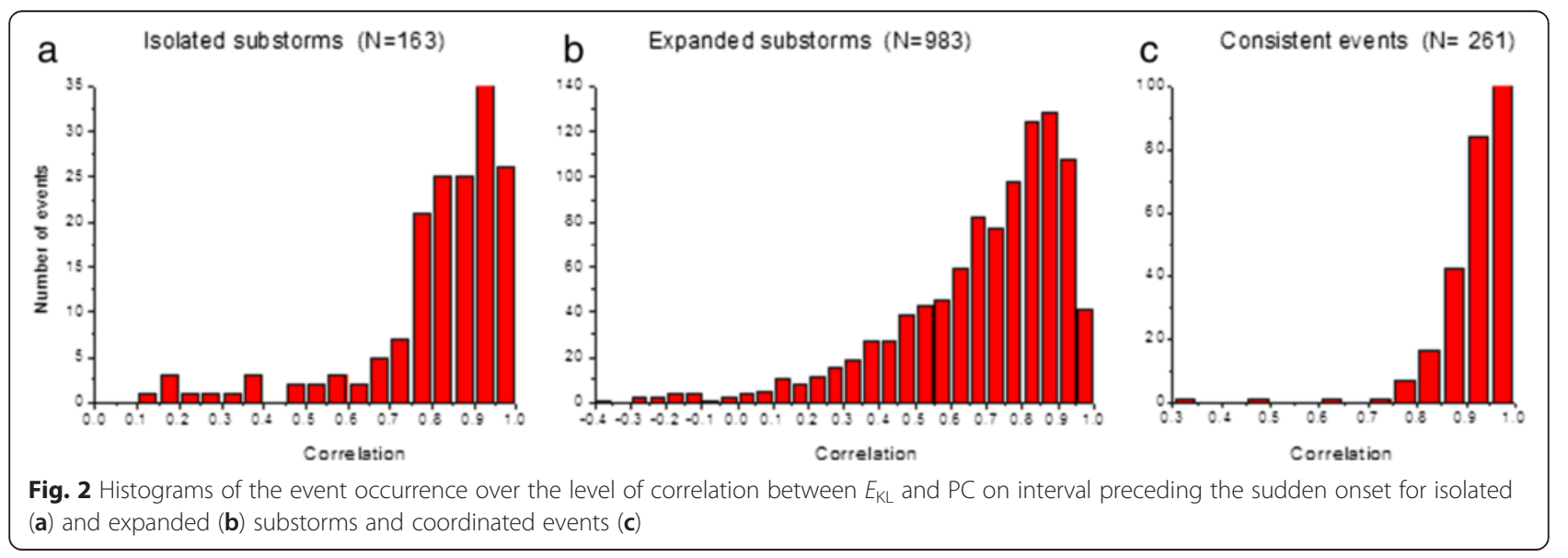


at least in $8 \%$ of examined substorms. It implies that the ground-based PC index provides more reliable evidence of the solar wind coupling with the magnetosphere, than the $E_{\mathrm{KL}}$ field derived from the solar wind measurements in the Lagrange point L1.

\section{Delay in the response of PC index to changes in $E_{\mathrm{KL}}$ field} To reveal the distinctive features in the response of PC to $E_{\mathrm{KL}}$ changes, we restricted our consideration to the most representative events demonstrating the high correlation $(R>0.75)$ between $\mathrm{PC}$ and $E_{\mathrm{KL}}$ field reduced to the magnetopause. The PC and $E_{\mathrm{KL}}$ quantities smoothed with the use of the 15-min smoothing running window were examined. Figure 3 shows the distribution of the number of examined events over the delay times $(\Delta T)$ of the $\mathrm{PC}$ response to the $E_{\mathrm{KL}}$ variations. The delay times are presented with a step of $3 \mathrm{~min}$, excluding events with zero and negative delay time, the latter events being united in one group irrespective of the actual negative value of $\Delta T$. One can see that delay times are extended in range from 0 to $40 \mathrm{~min}$ with the pronounced peak at $\Delta T=10-18 \mathrm{~min}$ for isolated substorms, $\Delta T=13-18 \mathrm{~min}$ for extended substorms, and $\Delta T=15-20 \mathrm{~min}$ for coordinated events. The same regularity has been obtained (Fig. 4) while separating the expanded substorms according to their intensity: maximal correlation between PC and $E_{\mathrm{KL}}$ was observed at $\Delta T=12-20 \mathrm{~min}$ irrespective of the substorm onset magnitude. It implies that the substorm intensity is not affected by the delay time $\Delta T$ value.

One can suggest that the shortest and longest values $\Delta T$ observed at the wings of the frequency curve with minimal incidence of events may be due to the random dispersion related, among other things, to the incorrect evaluation of the transport time while reducing the solar wind parameters from the Lagrange point, where they were measured, to the magnetopause. Figure 5 gives two examples of the obviously wrong evaluation of the transport time. In the event on April 6, 2000 (Fig. 5a), the substorm started 5 min ahead of the moment of the solar wind encounter with the magnetosphere, estimated at GSFC/SPDF OMNI/Web interface (http://omniweb.gsfc. nasa.gov). In the event on February 11, 2000 (Fig. 5b), the substorm beginning occurred to be coincident with the moment of the solar wind arrival to the magnetosphere. Since magnetic substorms are caused just by the action of the disturbed solar wind on magnetosphere and the definite time is required for the substorm development, we have to conclude that inconsistency between the $E_{\mathrm{KL}}$ time evolution and substorm onset moment in these cases should be attributed to the incorrect determination of transport time (evaluated solar wind speed turned out to be less than the actual speed).

One can see that the substorm onsets in both cases were related to the sudden increase of the PC index, in full agreement with the results presented in paper 1 . As our analysis showed, the negative delay times between the $E_{\mathrm{KL}}$ jump reduced to the magnetopause and the substorm onset (and, correspondingly, between the $E_{\mathrm{KL}}$ jump and the appropriate PC increase) occurred in range of $\Delta T$ from 0 to $-10 \mathrm{~min}$. The negative and zero delay times were encountered in about $1.5 \%$ of all examining events implying the limits of the incorrect evaluation of the $E_{\mathrm{KL}}$ transport time (and their input into the random dispersion).

\section{Role of the solar wind parameters}

To ascertain a possible influence of the solar wind parameters on value $\Delta T$, we examined the relationships between $\Delta T$ values and such solar wind parameters as the IMF vertical $\left(B_{\mathrm{Z}}\right)$, azimuthal $\left(B_{\mathrm{Y}}\right)$, and horizontal $\left(B_{\mathrm{T}}\right)$ components, the solar wind speed $\left(V_{\mathrm{sw}}\right)$ and solar wind dynamic pressure $\left(P_{\mathrm{d}}\right)$. The solar wind parameters were averaged for the same term that has been taken for correlation: 1-h interval preceding the moment of sudden onset $\left(T_{0}\right)$ in case of isolated and expanded substorms or interval $\left(T_{0} \pm 30 \mathrm{~min}\right)$ in case of coordinated events. Results of the analysis are presented in Fig. 6 (except for

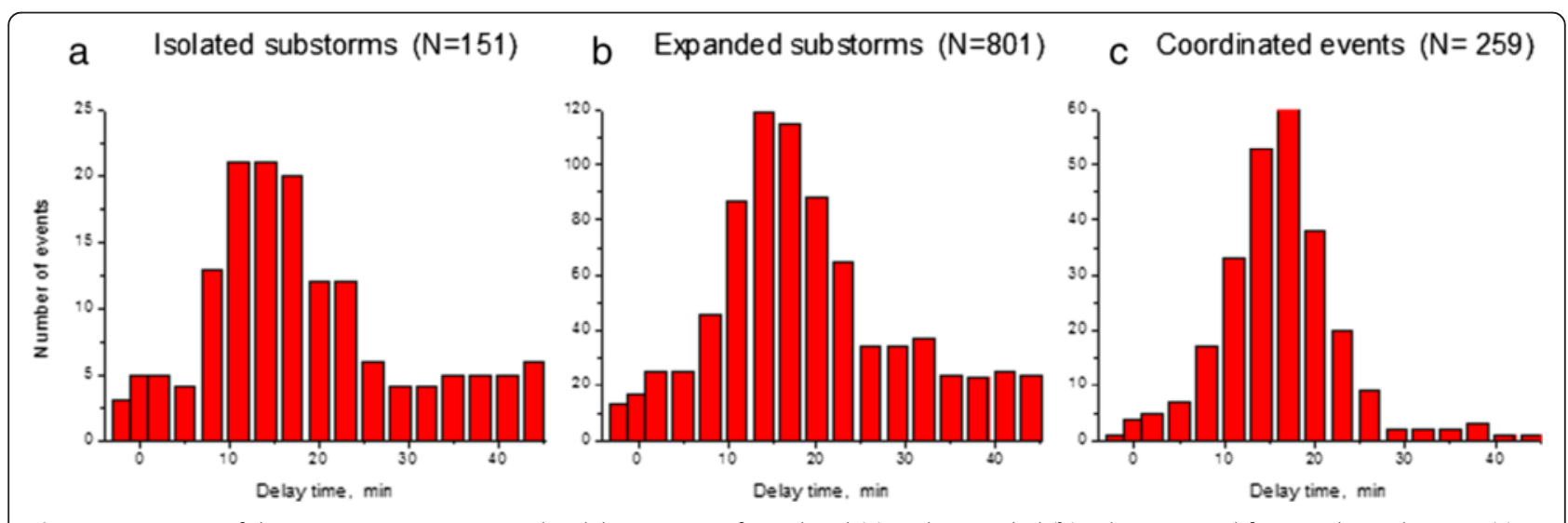

Fig. 3 Histograms of the event occurrence over the delay times $\Delta T$ for isolated (a) and expanded (b) substorms and for coordinated events (c) 


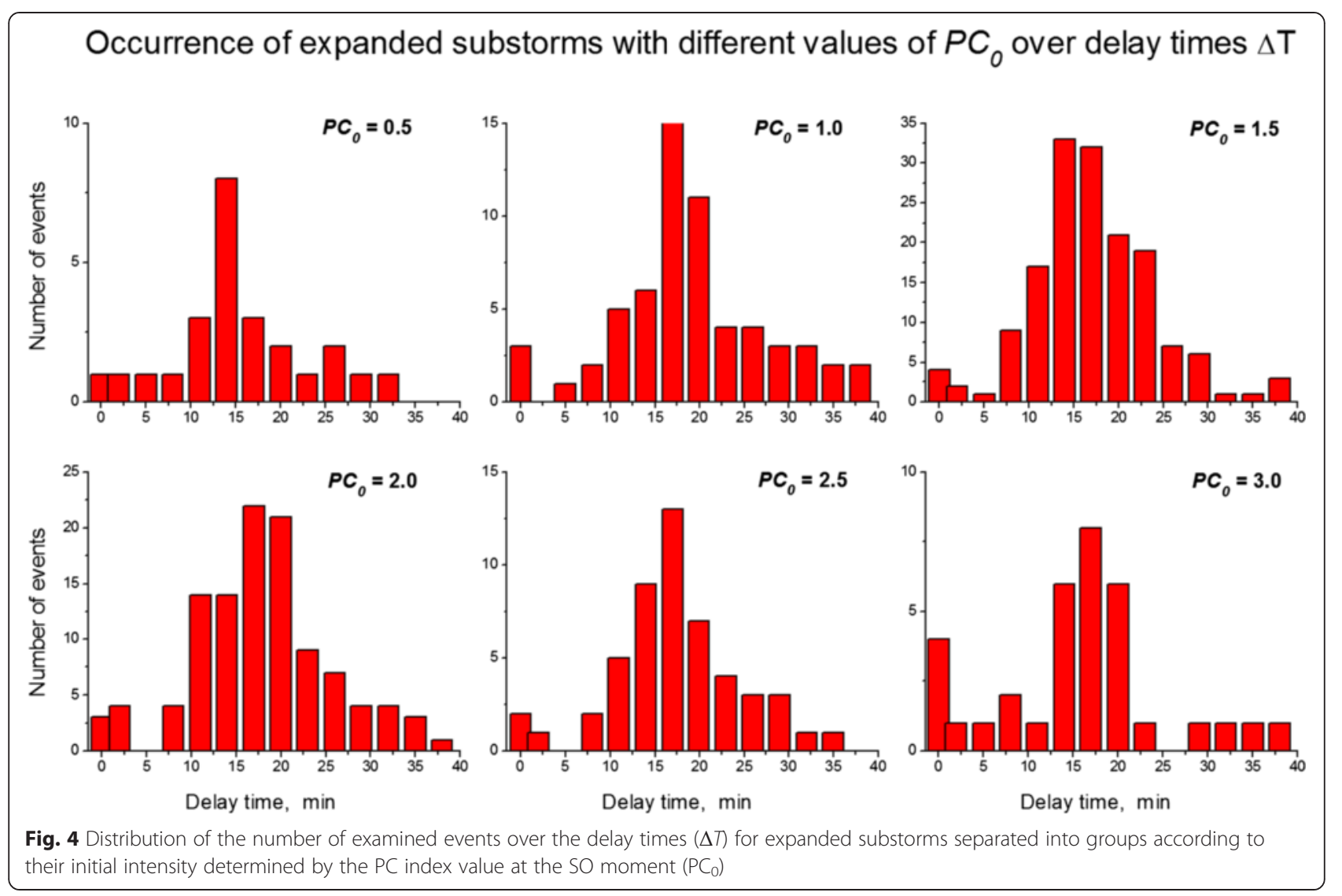

the IMF $B_{\mathrm{Y}}$ component, which is not exempted from the total regularity).

One can see that, contrary to the expectations, any single solar wind parameter is of minor importance in the $\Delta T$ value setting. In case of the solar wind speed, a slight tendency for a decrease of the $\Delta T$ value with the growth of $V_{\mathrm{sw}}$ is seen. Correspondingly, a slight tendency is seen for the delay time decrease with the solar wind dynamic pressure increase. In case of the IMF $B_{\mathrm{Z}}$ component, the $\Delta T$ value for isolated and expanded substorms demonstrates the tendency to be less with the positive $B_{\mathrm{Z}}$ quantities. Other solar wind parameters, such as the azimuthal and tangential IMF components, do not demonstrate any influence on the $\Delta T$ value.

To reveal the actual solar wind parameter controlling the value $\Delta T$, we dwelt on the coordinated events. Indeed, in case of isolated substorms, we deal with a too limited body of data, whereas in case of expanded substorms, the high level of the background magnetic activity can strongly modify the regular relations between $\Delta T$ and solar wind parameters. The 1 -min values $V_{\mathrm{X}}, B_{\mathrm{Z}}$, $E_{\mathrm{KL}}$, and $\mathrm{PC}$ fixed in the course of coordinated events were smoothed with the use of the boxcar average of the 15-min width, and then they were separated into different groups according to delay value $\Delta T$. Afterwards, the time evolutions of the smoothed values $V_{\mathrm{X}}, B_{\mathrm{Z}}, E_{\mathrm{KL}}$, and PC were put through the superposed epoch analysis, the moment of the sudden jump of the 15-min smoothed $E_{\mathrm{KL}}$ being taken as a zero time $T_{0}$.

Behavior of the smoothed values $V_{\mathrm{X}}, B_{\mathrm{Z}}, E_{\mathrm{KL}}$, and $\mathrm{PC}$ in the course of coordinated events is shown in Fig. 7 for the most statistically justified groups with $\Delta T=10-12 \mathrm{~min}$ $(N=33), \Delta T=13-15 \min (N=53), \Delta T=16-18 \mathrm{~min}$ $(N=60)$, and $\Delta T=19-21 \mathrm{~min}(N=38)$. The thin red lines represent the time evolution of $V_{\mathrm{X}}, B_{\mathrm{Z}}, E_{\mathrm{KL}}$, and $\mathrm{PC}$ in the course of individual events. Solid black lines show the behavior of the mean $V_{\mathrm{X}}, B_{\mathrm{Z}}, E_{\mathrm{KL}}$, and PC quantities for each $\Delta T$ group. The vertical lines mark the zero time $T_{0}$ and the moment when the PC index starts to increase $\left(T_{0}+\Delta T\right)$, i.e., the appropriate delay time interval.

One can see that the solar wind speeds $V_{\mathrm{X}}$ as large as $-800 \mathrm{~km} / \mathrm{s}$ and as small as $-300 \mathrm{~km} / \mathrm{s}$ are typical of any $\Delta T$ group, the time evolution of $V_{\mathrm{X}}$ being almost insensitive to the moment $T_{0}$. As a result, the tendency for the delay time decrease with increase of $\left|V_{\mathrm{X}}\right|$ value is hardly seen in Fig. 7. It implies that the solar wind speed by itself is not a decisive factor in the $\Delta T$ setting under the regular conditions. The IMF vertical $B_{\mathrm{Z}}$ component starts to turn down (southward) just at the moment $T_{0}$, the regularity being evident for individual events as well as for mean $B_{\mathrm{Z}}$ in each $\Delta T$ group: the higher the $B_{\mathrm{Z}}$ alteration magnitude $\left(\Delta B_{\mathrm{Z}}\right)$, the shorter the delay time $\Delta T$. 


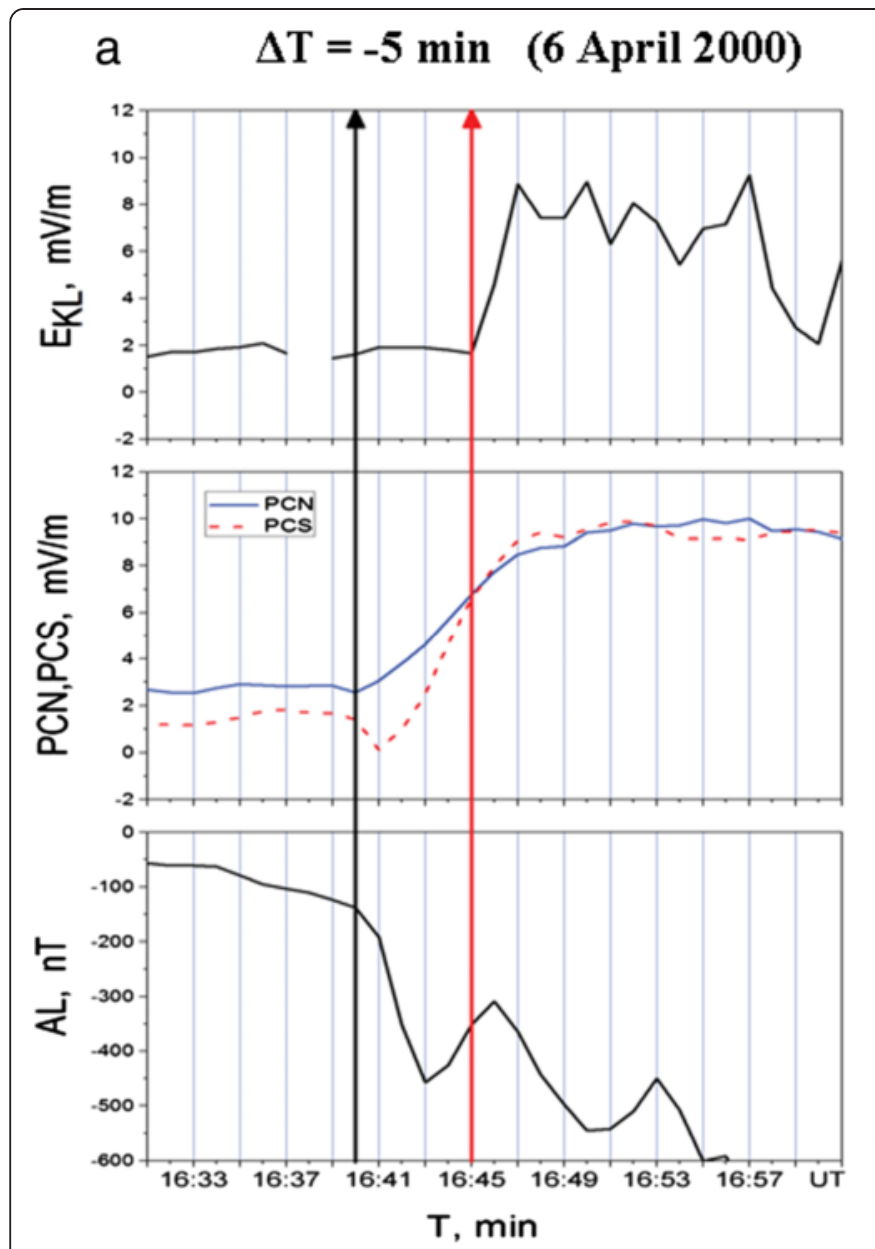

\section{b $\quad \Delta \mathrm{T}=0(11$ February 2000$)$}

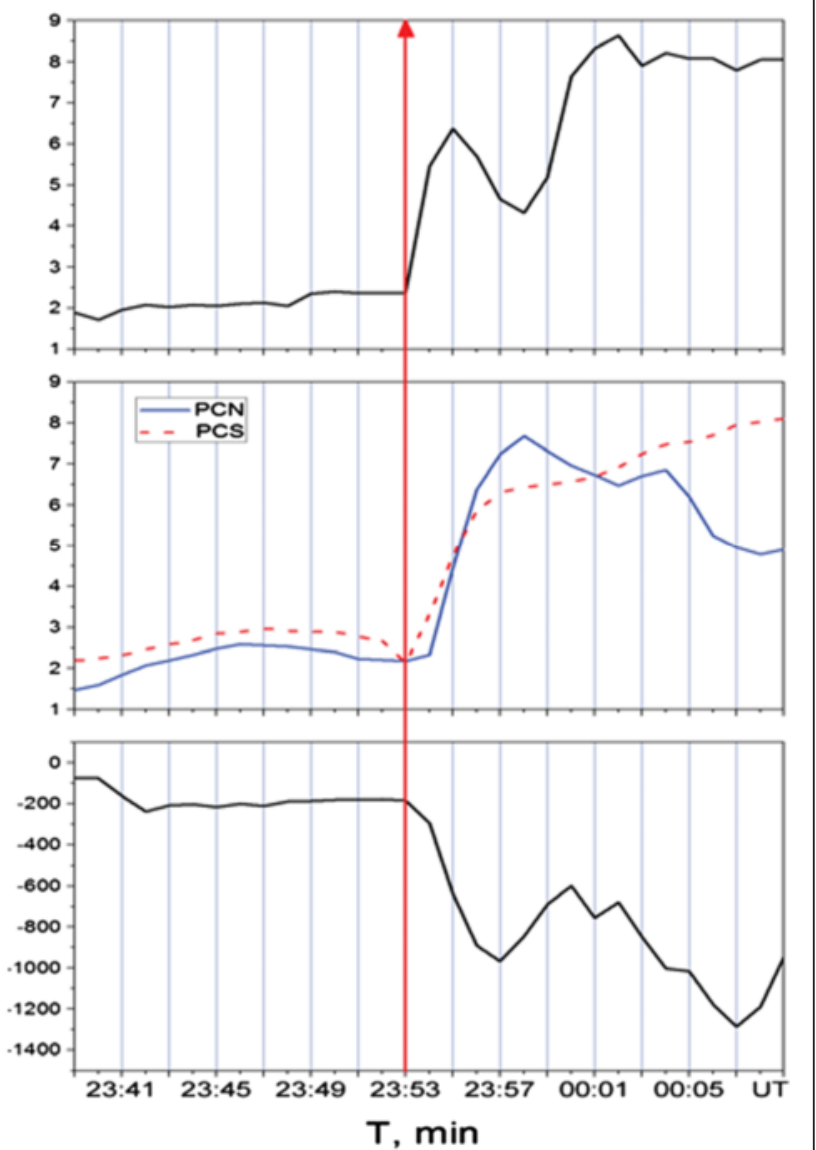

Fig. 5 Examples of events with the negative (a) and zero (b) delay time $\Delta T$. Moment of sharp rise of the $E_{\mathrm{KL}}$ field, reduced to the magnetopause, is marked by a red vertical line; the substorm onset is marked by a black line

However, the larger $\Delta B_{\mathrm{Z}}$ values are built up at the expense of positive (northward) $B_{\mathrm{Z}}$ preceding the moment $T_{0}$, whereas the final level of southward $B_{\mathrm{Z}}$ occurs to be almost the same for all $\Delta T$ groups (mean $B_{\mathrm{Z}} \sim-3.5 \mathrm{nT}$ ). As a result, the shortest delay times $\Delta T$ can be observed under conditions of the northward IMF (averaged for the 1-h interval), as Fig. $6 \mathrm{~b}$ has demonstrated. At the same time, correlation between $\Delta T$ and the $E_{\mathrm{KL}}$ field (which presents the product of the solar wind speed $V_{\mathrm{X}}$ and the IMF tangential component $B_{\mathrm{T}}=\left(B_{\mathrm{Y}}{ }^{2}+B_{\mathrm{Z}}{ }^{2}\right)^{1 / 2}$ taken with allowance for angle $\theta$ between the IMF transverse component and the geomagnetic dipole) turns out to be quite explicit: the higher the $E_{\mathrm{KL}}$ raise $\left(\Delta E_{\mathrm{KL}}\right)$ during the $\Delta T$ interval, the shorter the delay time.

\section{$E_{\mathrm{KL}}$ growth rate as a clue parameter determining delay time $\Delta T$}

Basing on the results presented in Figs. 6 and 7, we infer that the delay time $\Delta T$ is controlled not by separate solar wind parameter but rather by their growth rate. To reveal this peculiarity, we determine the gradients $\Delta V_{\mathrm{X}}, \Delta B_{\mathrm{Z}}$,
$\Delta E_{\mathrm{KL}}$, and their mean quantities for each particular interval $\Delta T$ and consider values $\Delta V_{\mathrm{X}} / \Delta T, \Delta B_{\mathrm{Z}} / \Delta T$, and $\Delta E_{\mathrm{KL}} /$ $\Delta T$ as a mean growth rate typical of each $\Delta T$ interval. Figure 8 depicts relationships between $\Delta T$ and the mean growth rates $\mathrm{d} V_{\mathrm{X}} / \mathrm{dt}, \mathrm{d} B_{\mathrm{Z}} / \mathrm{dt}$ and $\mathrm{d} E_{\mathrm{KL}} / \mathrm{dt}$ for all $\Delta T$ groups of coordinated events with number of events $n>4$. The thin vertical bars in Fig. 8 present the standard deviation (sd) of individual values $\mathrm{d} V_{\mathrm{X}} / \mathrm{dT}, \mathrm{d} B_{\mathrm{Z}} / \mathrm{dT}, \mathrm{d} E_{\mathrm{KL}} / \mathrm{dT}$ from their mean quantities in each $\Delta T$ group. The thick vertical bars present standard error of the mean values $\mathrm{d} V_{\mathrm{X}} / \mathrm{dT}$, $\mathrm{d} B_{\mathrm{Z}} / \mathrm{dT}$, and $\mathrm{d} E_{\mathrm{KL}} / \mathrm{dT}$ determination $\left(\mathrm{se}=\mathrm{sd} / n^{1 / 2}\right)$. As Fig. 8 shows, relationships between $\Delta T$ and mean growth rates are expressed by the linear law (solid lines):
(a) $\Delta T=24.1-18.26 *\left(\mathrm{~d} V_{\mathrm{X}} / \mathrm{dt}\right) \quad R=-0.80$
(b) $\Delta T=32.9+47.8 *\left(\mathrm{~d} B_{\mathrm{Z}} / \mathrm{dt}\right) \quad R=0.64$
(c) $\Delta T=57.1-392.1 *\left(\mathrm{~d} E_{\mathrm{KL}} / \mathrm{dt}\right) \quad R=-0.94$ 


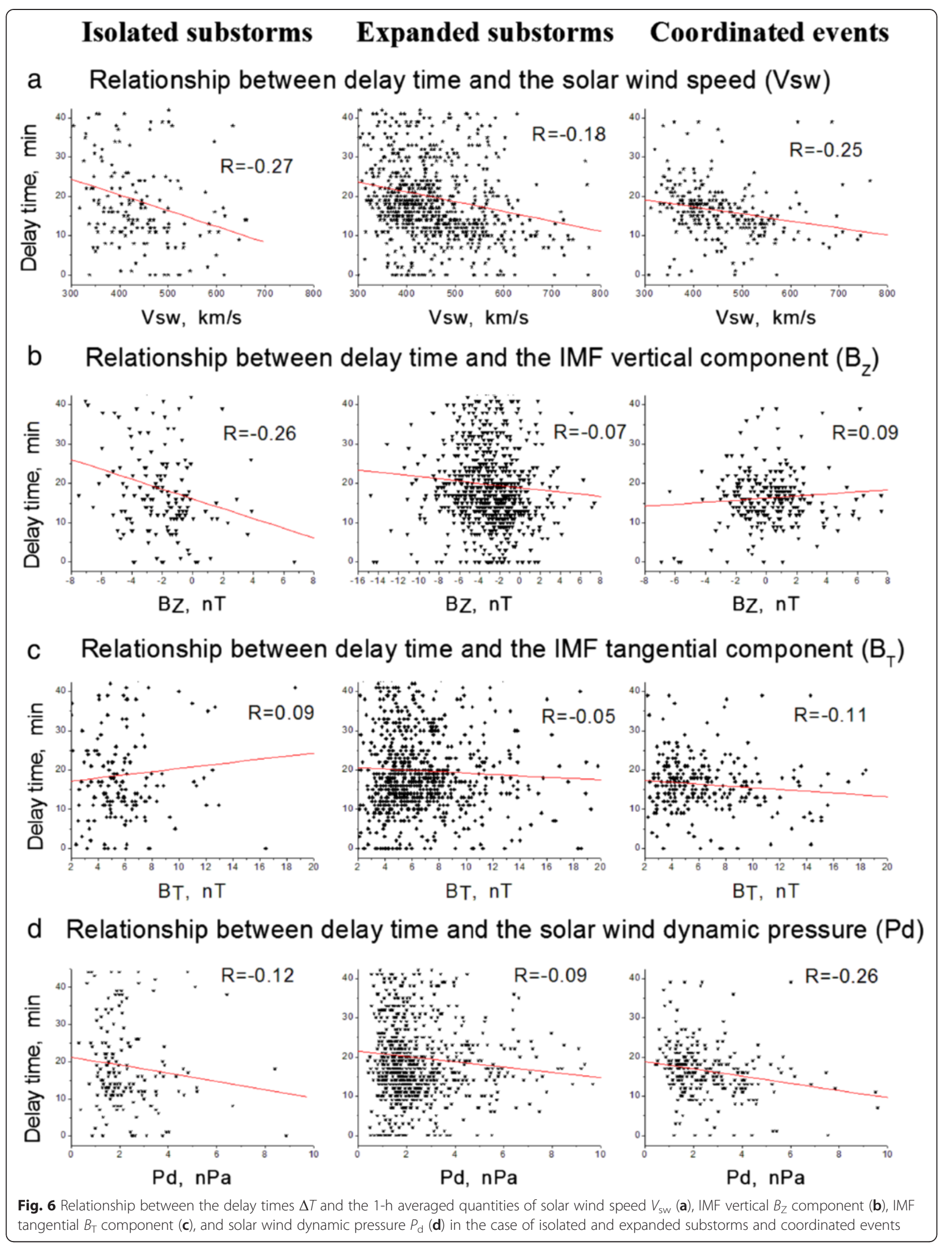




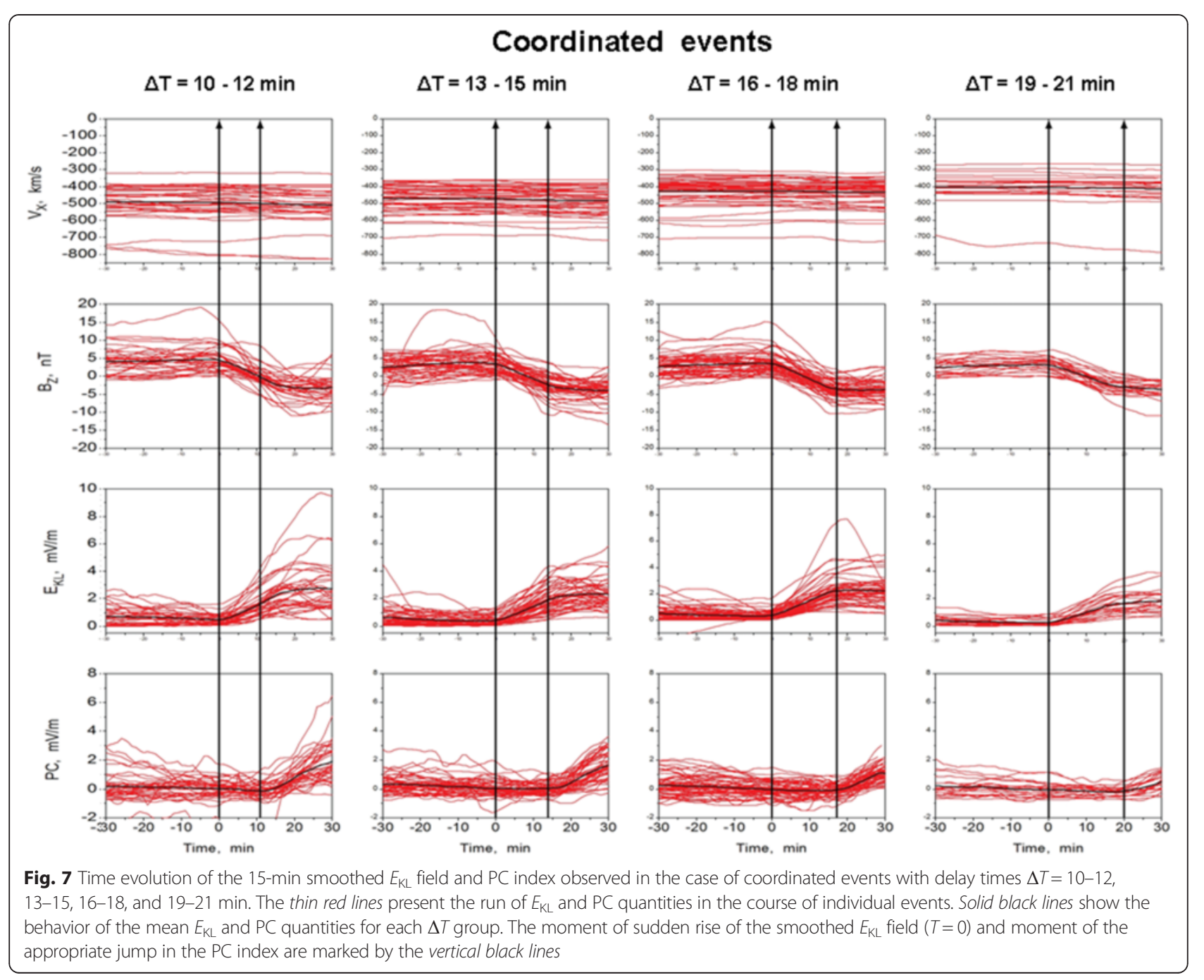

One can see that the $\Delta T$ value reduces as the quantities $\mathrm{d} V_{\mathrm{X}} / \mathrm{dt}$ and $\mathrm{d} E_{\mathrm{KL}} / \mathrm{dt}$ increase and $\mathrm{d} B_{\mathrm{Z}} / \mathrm{dt}$ decreases. It should be noted that changes of $V_{\mathrm{X}}$ on intervals $\Delta T>$ $10 \mathrm{~min}$ are quite negligible $\left(\mathrm{d} V_{\mathrm{X}} / \mathrm{dt}<0.5 \mathrm{~km} / \mathrm{s} / \mathrm{min}\right)$ in spite of rather high level of correlation between $\Delta T$ and $\mathrm{d} V_{\mathrm{X}} / \mathrm{dt}$; in addition, the standard deviation in this case is in excess of $200 \%$. Change of $\mathrm{d} B_{\mathrm{Z}} / \mathrm{dt}$ on intervals $\Delta T$ is more noticeable, the standard deviation being less than $100 \%$, but correlation between $\Delta T$ and $\mathrm{d} B_{\mathrm{Z}} / \mathrm{dt}$ is much worse $(R=0.64)$. The delay time $\Delta T$ is in the best association with the $E_{\mathrm{KL}}$ growth rate $\left(\mathrm{d} E_{\mathrm{KL}} / \mathrm{dt}\right)$, the sd values being about $75 \%$ of the mean quantity in this case. These experimental facts are indicative of primary importance of $\mathrm{d} E_{\mathrm{KL}} / \mathrm{dt}$ for the delay time setting in the PC response to the solar wind variations.

\section{Discussion}

Mechanisms of the substorms triggering is still being discussed. The commonly accepted idea is that substorms are triggered by geoeffective changes in the solar wind parameters. The alternative concept suggests that substorms can be triggered by internal process (Hsu and McPherron 2003; Liu et al. 2011; McPherron et al. 1986). Indeed, occurrence of moderate and even intense substorms under conditions of relatively steady interplanetary (northward) magnetic field was noted in many studies (e.g., (Kullen and Karlsson 2004; Lee et al. 2007; Wu et al. 2002)). Special attention to intense substorms developed under conditions of persistently northward IMF was given by Lee et al. (2010) with the use of the UV auroral images on board the IMAGE spacecraft and other complementary observations such as magnetic dipolarizations and energetic particle injections on geosynchronous orbit (the GOES and LANL spacecraft measurements). The conclusion was made that occurrence of such substorms implies a large amount of energy remained in the tail even under northward IMF impact on the magnetosphere.

Troshichev et al. (2011) tested the substorms examined by Lee et al. (2010) in their relation to interplanetary 

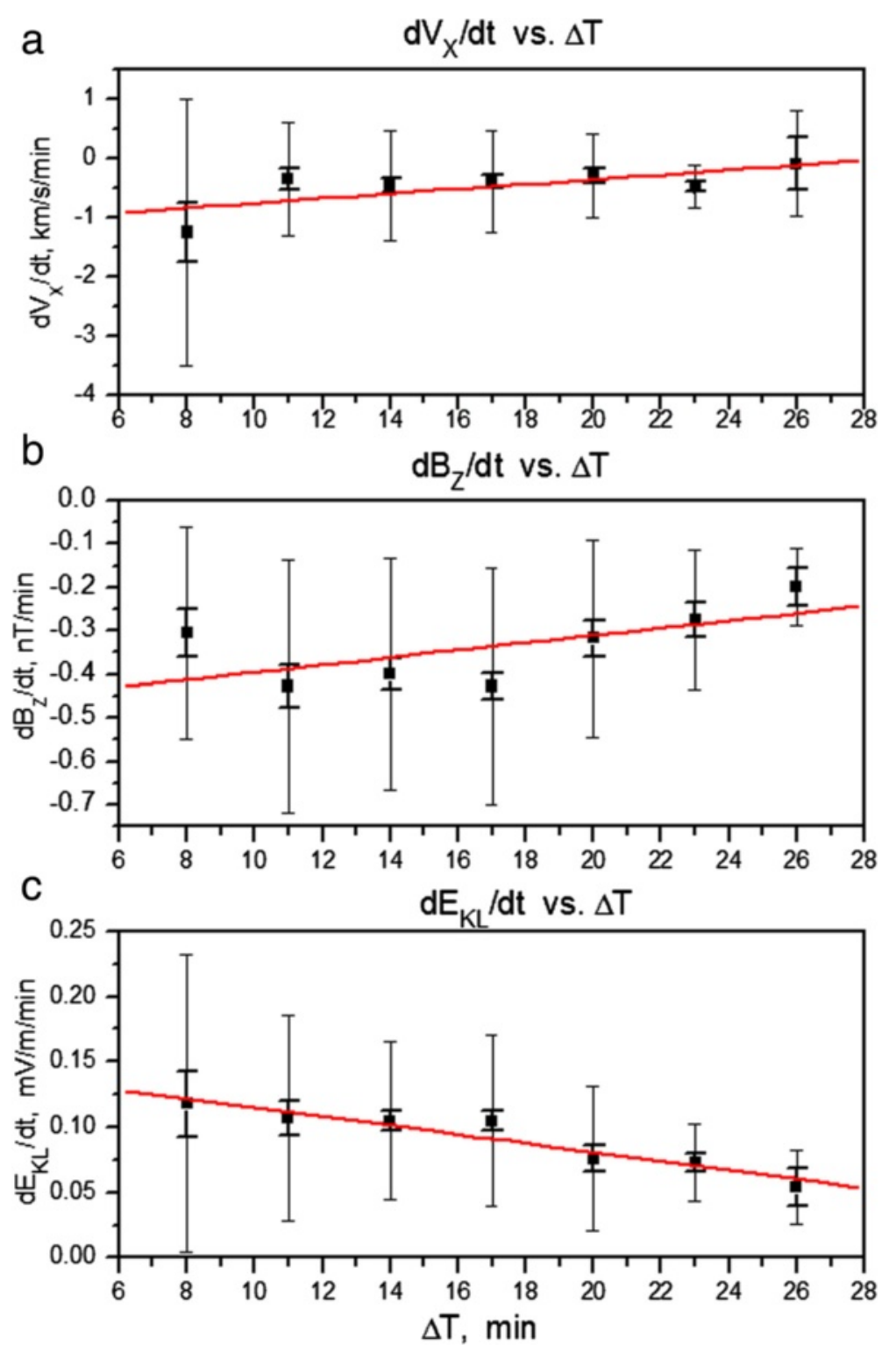

Fig. 8 Relationships between the delay time $\Delta T$ and the mean growth rates $d V_{\chi} / d t(\mathbf{a}), d B_{z} / d t(\mathbf{b})$, and $d E_{K L} / d t$ (c) based on the analysis of coordinated events. Thin vertical bars present the standard deviation (sd) of individual values $\Delta V_{X} / \Delta T, \Delta B_{Z} / \Delta T$, and $\Delta E_{\mathrm{KL}} / \Delta T$ from their mean quantities in each $\Delta T$ group; thick vertical bars present the standard error of the mean quantity determination

electric field $E_{\mathrm{KL}}$ and the PC index. It turned out that values $E_{\mathrm{KL}}$ and $\mathrm{PC}$ in all cases were in excess of the threshold level $\sim 1.5 \mathrm{mV} / \mathrm{m}$, which is required for the ordinary substorm development. The $E_{\mathrm{KL}}$ rising on intervals preceding the substorm onset was attained at the expense of the IMF azimuthal component, which is taken into account in the $E_{\mathrm{KL}}$ field (with allowance for tilt angle, see expression (1), as distinct from the electric field $E_{\mathrm{Y}}=V_{\mathrm{SW}} B_{\mathrm{Z}}$ examined in the abovementioned papers. As this takes place, the PC index, characterizing the polar cap magnetic activity affected by $E_{\mathrm{KL}}$, demonstrates the evident relation to the substorm onset. The conclusion was made by
Troshichev et al. (2011) that substorms considered by Lee et al. (2010), as exclusive events, turn out to be a quite ordinary phenomena, if the proper coupling function $E_{\mathrm{KL}}$ and the corresponding $\mathrm{PC}$ index are taken into examination.

Thus, use of the interplanetary electric $E_{\mathrm{KL}}$ field instead of the $E_{\mathrm{Y}}$ field makes needless a hypothetical mechanism of the energy storage in the magnetotail under conditions of ineffective northward IMF and calls into question the concept of nontriggered substorms. It would appear reasonable that substorms, occurring with clearly defined foregoing PC jump but without any 
evident precursor in the $E_{\mathrm{KL}}$ field, testify to the fact that solar wind measured on board the ACE spacecraft (positioned in the Lagrange point L1) did not encounter the Earth's magnetosphere. Comparison of the $E_{\mathrm{KL}}$ and PC time evolutions before the substorm onset makes it possible to separate these rare events. Accordingly, the PC index can be used as a basic guideline in choosing the optimal coupling function (as it was made, for example, by Gao et al. (2012)).

Analysis of delay times $\Delta T$ in the response of the PC index to the $E_{\mathrm{KL}}$ variations (reduced to the magnetopause) showed, in full consistency with many other experimental data, that $12-20 \mathrm{~min}$ is a typical time for the solar wind energy transmission from the magnetopause to polar caps. The value of the actual delay time is determined by the $E_{\mathrm{KL}}$ field growth rate, not by separate solar wind parameters. The negative and zero $\Delta T$ values, resulted in some cases, should be regarded as indicative of wrong evaluation of time required for the $E_{\mathrm{KL}}$ transferring from the ACE spacecraft position to the magnetopause.

Statistical dependence of $\Delta T$ on such solar wind parameters, as the IMF $B_{\mathrm{Z}}$ component and the solar wind speed $V_{\mathrm{sw}}$ averaged for 1-h interval preceding the substorm sudden onset, is negligibly small. This fact is in evident conflict with the commonly accepted concept of reconnection of the interplanetary and geomagnetic field lines (Dungey 1961), as a mechanism providing the response of electric fields in the polar ionosphere to the solar wind variations. Indeed, one might expect from the Dungey's concept that the reconnection process should be controlled by southward IMF component and the delay time $\Delta T$ should be rigidly related to the speed of the reconnecting field lines moving in space, i.e., to the solar wind speed. In actuality, the delay time value is dependent on the growth rates $\mathrm{d} V_{\mathrm{X}} / \mathrm{dt}, \mathrm{d} B_{\mathrm{Z}} / \mathrm{dt}$, and $\mathrm{d} E_{\mathrm{KL}} / \mathrm{dt}$, the $E_{\mathrm{KL}}$ field growth rate $\left(\mathrm{d} E_{\mathrm{KL}} / \mathrm{dt}\right)$ being the main factor in the delay time setting.

In the framework of Dungey's concept, the renewed convection cells related to the southward IMF strengthening should expand across the polar cap in conformity with the solar wind speed. It will take about $20 \mathrm{~min}$ for $V_{\mathrm{X}} \sim-400 \mathrm{~km} / \mathrm{s}$, not $\sim 7 \div 10 \mathrm{~min}$ min observed in actuality. The mechanism other than the reconnection of interplanetary and geomagnetic field lines is required to interpret the observed lowest limits of delay time. From the alternative point of view (see, for example, Antonova and Tverskoy (1998) and Troshichev and Janzhura (2012a)), the polar cap magnetic activity is generated by the magnetospheric region 1 field-aligned currents, and these currents are created on account of the plasma gradients, which are permanently formed within the closed magnetosphere owing to the solar wind impact on the magnetosphere.
As the results of Stauning and Troshichev (2008) and Troshichev et al. (2007) show, the solar wind dynamic pressure is the second, after $E_{\mathrm{KL}}$, most important factor for the PC index increase, the PC index being affected by the pressure growth rate (i.e., jump power $\Delta P_{\mathrm{SW}} / \Delta T$ ), not by pressure level. It should be noted in this connection that results (Stauning and Troshichev 2008) demonstrate that impact of the solar dynamic pressure pulses on magnetosphere leads to enhancement of the dayside cusp and region 1 FAC systems, the latter currents being located deeply within the closed magnetosphere. The mechanisms for regulation of both, region 1 and cusp, FAC systems are not well recognized and should be a subject of special investigation.

\section{Conclusions}

Statistical analysis of the relationship between the interplanetary electric field $E_{\mathrm{KL}}$ and the magnetic activity index PC was fulfilled for events with isolated and expanded substorms and for events with coordinated alterations in $E_{\mathrm{KL}}$ and $\mathrm{PC}$. The analysis has demonstrated that the PC index strongly follows the time evolution of $E_{\mathrm{KL}}$ field on intervals preceding the substorm onset: correlation $R>0.5$ was observed for more than $90 \%$ of isolated substorms, for $\sim 80 \%$ of expanded substorms, and for $99 \%$ of coordinated events. A minor or even negative correlation between $E_{\mathrm{KL}}$ and PC obtained for about $10 \%$ of substorms suggests that the solar wind flow, measured in the Lagrange point (about 1.5 million kilometers from the magnetosphere), did not encounter the magnetosphere in these cases.

The following results have been obtained while examining the delay times $\Delta T$ in the response of the PC index to the $E_{\mathrm{KL}}$ field variations in case of the coordinated events:

- The delay times $\Delta T$ are not related to the value of separate solar wind parameters, such as solar wind speed and IMF $B_{\mathrm{Z}}$ components, contrary to general conviction.

- The $\Delta T$ value is controlled by the growth rate of $E_{\mathrm{KL}}$ field.

- The lower values of delay time $(\Delta T \sim 5 \mathrm{~min})$ are observed in case of extremely strong and sharp rise of the $E_{\mathrm{KL}}$ field.

- $\mathrm{PC}$ index provides possibility to verify the time of the solar wind flow transportation from ACE position (where the solar wind speed is estimated) to the magnetosphere.

The set of these results in combination with data testifying that the substorm onsets are related to the PC precursors (see paper 1) demonstrates that the PC index is an adequate ground-based indicator of the solar wind 
energy incoming into the magnetosphere. The PC index might be useful in fitting the solar wind-magnetosphere coupling function, monitoring and nowcasting the magnetosphere state, and resolving other problems which require the actual information about the solar windmagnetosphere-ionosphere interaction.

\section{Competing interests}

The authors declare that they have no competing interests.

\section{Authors' contributions}

OAT The idea of study, conception of paper, interpretation of results. DAS Acquisition of data and the statistical analysis, interpretation of results. Both authors participated in preparation and revising the manuscript. Both authors read and approved the final manuscript

\section{Acknowledgements}

The solar wind and IMF data were obtained from the GSFC/SPDF OMNI/Web interface at http://omniweb.gsfc.nasa.gov. The PCN and PCS indices are published online at web address: http://pc-index.org.

Received: 2 April 2015 Accepted: 6 October 2015

Published online: 21 October 2015

\section{References}

Antonova EE, Tverskoy BA. On the nature of electric fields in the Earth's inner magnetosphere. Geomagn Aeronomy Int. 1998;1 (1):9-21.

Dungey JW. Interplanetary magnetic field and the auroral zones. Phys Rev Lett. $1961 ; 6: 47-8$.

Gao Y, Kivelson MG, Ridley AJ, Weygand JM, Walker RJ. Utilizing the polar cap index to explore strong driving of polar cap dynamics. J Geophys Res. 2012;117:A7. doi:10.1029/2011JA017087.

Hsu T-S, McPherron RL. Occurrence frequencies of IMF triggered and nontriggered substorms. J Geophys Res. 2003;108(A7):1307. doi:10.1029/ 2002JA009442.

Kan JR, Lee LC. Energy coupling function and solar wind-magnetosphere dynamo. Geophys Res Lett. 1979;6:577-80.

Kullen A, Karlsson T. On the relation between solar wind, pseudobreakups, and substorms. J Geophys Res. 2004;109:A12218. doi:10.1029/2004JA010488.

Lee DY, Lyons LR, Weygand JM, Wang CP. Reasons why some solar wind changes do not trigger substorms. J Geophys Res. 2007;112:A06240. doi:10.1029/2007JA012249.

Lee DY, Choi KC, Ohtani S, Lee JH, Kim KC, Park KS, et al. Can intense substorms occur under northward IMF conditions? J Geophys Res. 2010;115:A01211. doi:10.1029/2009JA014480.

Liu J-M, Zhang B-C, Kamide Y, Wu Z-S, Hu Z-J, Yang H-G. Spontaneous and trigger-associated substorm compared: electrodynamic parameters in the polar ionosphere. J Geophys Res. 2011;116:A01207. doi:10.1029/2010JA 015773.

McPherron RL, Terasawa T, Nishida A. Solar wind triggering of substorm expansion phase. J Geomagn Geoelectr. 1986;38(11):1089-108.

Newell PT, Sotirelis T, Liou K, Meng C-I, Rich FJ. A nearly universal solar wind magnetosphere coupling function inferred from 10 magnetospheric state variables. J Geophys Res. 2007;112:A01206. doi:10.1029/2006JA012015.

Newell PT, Sotirelis T, Liou K, Rich FJ. Pairs of solar wind-magnetosphere coupling functions: combining a merging term with a viscous term works best. J Geophys Res. 2008;113:A04218. doi:10.1029/2007JA012825.

Stauning $\mathrm{P}$, Troshichev OA. Polar cap convection and PC index during sudden changes in solar wind dynamic pressure. J Geophys Res. 2008;113:A08227. doi:10.1029/2007JA012783.

Troshichev OA, Andrezen VG. The relationship between interplanetary quantities and magnetic activity in the southern polar cap. Planet Space Sci. 1985;33:415.

Troshichev O, Andrezen V, Vennerstrom S, Friis-Christensen E. Magnetic activity in the polar cap—a new index. Planet Space Sci. 1988;36:1095.

Troshichev O, Janzhura A, Stauning P. Magnetic activity in the polar caps: relation to sudden changes in the solar wind dynamic pressure. J Geophys Res. 2007; 112: doi:10.1029/2007JA012369
Troshichev OA, Podorozhkina NA, Janzhura AS. Relationship between PC index and magnetospheric substorms observed under conditions of northward IMF. J Atmos Solar-Terr Phys. 2011;73:2373-8.

Troshichev O, Janzhura A. Space weather monitoring by ground-based means: PC index. Berlin, Heidelberg: Springer Verlag; 2012a. p. 288. doi:10.1007/9783-642-16803-1.

Troshichev O, Janzhura A. Physical implications of discrepancy between summer and winter PC indices observed in the course of magnetospheric substorms. Adv Space Res. 2012b;50:77-84. doi:10.1016/j.asr.2012.03.017.

Troshichev OA, Podorozhkina NA, Sormakov DA, Janzhura AS. PC index as a proxy of the solar wind energy that entered into the magnetosphere: (1) Development of magnetic substorms, J. Geophys. Res. Space Physics. 2014; 119, doi:10.1002/2014JA019940.

Wang C, Han JP, Li H, Peng Z, Richardson JD. Solar wind-magnetosphere energy coupling function fitting: results from a global MHD simulation. J Geophys Res Space Physics. 2014; 119, doi:10.1002/2014JA019834.

Wu CC, Liou K, Lepping RP, Meng Cl. Observations of substorms during prolonged northward IMF conditions. In: Winglee RM, editor. Sixth Int Conf on Substorms. Seattle: Univ of Wash Press; 2002. p. 376.

\section{Submit your manuscript to a SpringerOpen ${ }^{\odot}$ journal and benefit from:}

- Convenient online submission

- Rigorous peer review

- Immediate publication on acceptance

- Open access: articles freely available online

- High visibility within the field

- Retaining the copyright to your article

Submit your next manuscript at $\boldsymbol{\wedge}$ springeropen.com 